\title{
A competência em informação como movimento de inovação social
}

\author{
Guilherme Goulart Righetto* \\ Elizete Vieira Vitorino*
}

Artículo recibido:

27 de febrero de 2019

Artículo aceptado:

17 de mayo de 2019

Artículo de revisión
Resumo

O artigo objetiva apontar a competência em informação, movimento que consiste na aprendizagem ao longo da vida, relacionada e vislumbrada como movimento de inovação social. Partindo do pressuposto que a inovação social possui características singulares - em função de o processo estar focalizado na satisfação de necessidades humanas (e no empowerment) por meio da inovação nas relações sociais - procura-se, ao longo da discussão, apresentar semelhanças e alinhamentos entre as principais temáticas, por meio da revisão de literatura, de caráter preponderantemente qualitativo. Assim, o corte realizado se efere aos entendimentos

* Programa de Pós-Gradação em Ciência da Informação, Universidade Federal de Santa Catarina (PGCI-UFSC), Brasil 
que potencialmente tornam a competência em informação um movimento de inovação social, apresentando por meio de ilustrações as possíveis conexões e aplicações desse movimento. Por fim, conclui-se que apesar das barreiras e lacunas existentes, as inovações sociais se ressignificam e evoluem por meio do aprendizado e do seu compartilhamento, transformando as ideias em formas atuais e correspondentes às sociedades contemporâneas, vislumbrando a resolução de conflitos recorrentes e sendo força motriz no aprendizado contínuo - daí a imersão da competência em informação como movimento desse contexto.

Palavras-chave: Competência em informação; Inovação social; Aprendizado ao longo da vida

\section{La alfabetización informacional como movimiento de innovación social \\ Guilherme Goulart Righetto y Elizete Vieira Vitorino}

\section{RESUMEN}

El artículo apunta a la alfabetización informacional, movimiento que consiste en el aprendizaje, a lo largo de toda la vida, relacionado y vislumbrado como movimiento de innovación social. Partiendo del supuesto de que la innovación social posee características singulares -en función de que el proceso esté enfocado a la satisfacción de necesidades humanas (y en el empowerment-empoderamiento) a través de la innovación en las relaciones sociales- se busca, a lo largo de la discusión, presentar semejanzas y alineaciones entre las principales temáticas por medio de la revisión de una literatura, de carácter preponderantemente cualitativo. Así, el corte realizado se refiere a los entendimientos que potencialmente hacen de la alfabetización informacional un movimiento de innovación social, presentando, por medio de ilustraciones, las posibles conexiones y aplicaciones de ese movimiento. Se concluye que, a pesar de las barreras y lagunas existentes, las innovaciones sociales se resignifican y evolucionan a través del aprendizaje y de compartirlas, transformando las ideas en formas actuales y correspondientes a las sociedades contemporáneas, vislumbrando la resolución de conflictos recurrentes y siendo fuerza motriz en el aprendizaje continuo - de ahí la inmersión 
de la alfabetización informacional como movimiento de ese contexto.

Palabras clave: Alfabetización Informacional; ALFIN; Innovación Social; Aprendizaje a lo largo de la Vida

Information literacy as a social innovation movement Guilherme Goulart Righetto and Elizete Vieira Vitorino

\begin{abstract}
The article aims at pointing to information literacy, a movement that consists of a lifelong learning, related and envisaged as a social innovation movement. Beginning with the assumption that social innovation has singular characteristics - due to the fact that the process is focused on human needs satisfaction (and empowerment) through innovation in social relations- it is sought throughout the discussion, to present similarities and alignments between the main thematic, through the literature review of predominantly qualitative nature. Thus, the realized cut refers to the understandings that potentially make the competence in information a movement of social innovation, presenting by means of illustrations the possible connections and applications of this movement. Finally, it is concluded that, despite the existing barriers and gaps, social innovations re-signify and evolve through learning and sharing, transforming ideas into current forms which correspond to contemporary societies, envisioning the resolution of recurring conflicts and being a driving force in continuous learning -hence the information literacy immersion as a movement of that context.
\end{abstract}

Keywords: Information Literacy; Social Innovation; Lifelong Learning

\title{
INTRODUÇÃO
}

Tndubitavelmente, situamo-nos num momento cujos desenvolvimentos científicos/técnicos globalizados e a proliferação desenfreada das desigualdades e da injustiça são conjunturas das quais somos reféns: seja como 
região, país, sujeito singular ou plural. Daí a premência de temáticas interdisciplinares que efetivamente promovam ao sujeito, a voz participativa e, consequentemente, a cidadania; além da absorção teórico-conceitual-empírica da vulnerabilidade em informação como categoria política e social, alocada no cerne de crises contemporâneas, tais como a liquidez de laços sociais no trabalho, no cotidiano, e na intolerância às diferenças humanas (Oviedo e Czeresnia, 2015).

Demo (2000) se atenta ao fato das "ambivalências da sociedade da informação", ou melhor, da onipresente "economia da informação", em que a competitividade econômica é respaldada na produção e no uso intensivo de conhecimento adquirido. Isto revela a real face desta sociedade da informação/conhecimento - cuja "mais-valia relativa" é atrelada pela ciência e tecnologia. Assim, "[...] a produtividade econômica é alimentada essencialmente, não mais pela força física do trabalhador, mas por sua inteligência". (Demo, 2000:38).

A modernidade, de forma similar, como todas as outras quase totalidades que se pretende retirar do fluxo contínuo do ser, torna-se esquiva: descobre-se que seu conceito é robusto de ambiguidade, "[...] ao passo que seu referente é opaco no miolo e puído nas beiradas. De modo que é improvável que se resolva a discussão". O aspecto conceitual da modernidade é naturalmente ambivalente (Bauman, 1999: 13). Dentre a multiplicidade de afazeres utópicos que a modernidade se atribuiu e que fizeram dela o que é, sobressai a da ordem (mais precisamente e de forma mais importante, a da ordem como tarefa) como a menos atingível das inatingíveis e a menos disponível das indispensáveis; "[...] e como o arquétipo de todas as outras tarefas, uma tarefa que torna todas as demais meras metáforas de si mesmas. A ordem é o contrário do caos; este é o contrário daquela. Ordem e caos são gêmeos modernos", concebidos em meio à ruptura e colapso do mundo ordenado que apenas existia como mundo, sem pensar jamais em como ser (Bauman, 1999: 12).

Assim, viver conforme a natureza requer vias de planejamento, esforço organizado e vigilante monitoramento. "Nada é mais artificial que a naturalidade; nada é menos natural do que se lançar ao sabor das leis da natureza. O poder, a repressão e a ação propositada se colocam entre a natureza e essa ordem socialmente produzida na qual a artificialidade é natural" (Bauman, 1999: 15). E neste contexto, surge a existência moderna na medida em que ela é produzida e sustentada por quatro perspectivas: projeto, manipulação, administração e planejamento. Portanto, a existência é moderna - e tão somente - mediante a administração por agentes capazes (isto é, que possuem conhecimento, habilidade e tecnologia) e soberanos. Tais agentes são soberanos na medida em que podem reivindicar e defender majestosamente o 
direito de gerenciar e administrar sua existência: "[...] o direito de definir a ordem e, por conseguinte, pôr de lado o caos como refugo que escapa à definição" (Bauman, 1999: 15).

Quando se trata de pensar nas assimetrias de soberanias autônomas e no referente à inserção desta na era da informação e do conhecimento, duas grandes questões se apresentam: em primeiro, as disparidades no campo da ciência, tecnologia e inovação; e, em segundo, as desigualdades no acesso às Tecnologias da Informação e Comunicação (TIC) - o digital divide. No primeiro aspecto, mundos científicos díspares são sedimentados. A agenda de pesquisa em Ciência e Tecnologia (C\&T), bem como a aplicação prática dessas pesquisas se mostram preponderantemente rasas em questões que não abrangem as reais necessidades ou os temas prioritários da maioria da população mundial e/ou localizada nos países em desenvolvimento (Albagli e Maciel, 2011).

Apesar de alguns exemplos de iniciativas em pesquisas enfatizadas nos países/grupos vulneráveis sendo realizados, ainda são precários, dado os insumos necessários e a profundidade do problema. Ações filantrópicas, grupos de ação social, Organizações Não-Governamentais (as ONG), e outros, geralmente em pequena escala, são concebidos e divulgados. Programas oficiais às epidemias contemporâneas, como o analfabetismo, à fome, às drogas e às doenças crônicas têm salientado o grau de vulnerabilidade social presente. A adesão constante dos movimentos sociais procura preencher lacunas deixadas pela retração ou pela inação do Estado. No entanto, o acúmulo por décadas de marginalização detém inúmeras causas e poucas soluções. A inovação social, surge então como uma das formas de se buscar alternativas viáveis para o futuro da sociedade humana (Bignetti, 2011).

Dentre as variações conceituais existentes, a inovação social é delineada por Bignetti (2011) como efeito do conhecimento aplicado às necessidades sociais mediante a participação e a cooperação de múltiplos atores sociais, viabilizando soluções novas e duradouras para grupos sociais, comunidades ou para a sociedade em geral. No atual contexto social, da onipresente economia da informação, observa-se que muitas das necessidades sociais e dos insumos para se fazer presente socialmente surgem pelas premências informacionais.

Neste prisma, e na acepção de Dudziak (2001) é que emerge o movimento da competência em informação (information literacy), cuja finalidade visa a formação de indivíduos capazes de determinar a natureza e a longitude de suas necessidades informacionais; além de propiciar a tomada de decisões concreta e coerente, detentoras do universo da informação e aptas a identificar efetivamente com as informações existentes, independente de formatos e/ou suportes; indivíduos que se apropriem da informação com ética, responsabilidade, criticidade e mestria, gerando novas informações e demandas ao longo de sua existência humana. 
O tom do discurso desse movimento é claramente o de exortação e de urgência para as mudanças demandadas na contemporaneidade: diz respeito à uma estratégia retórica centralizada na persuasão e que busca levar os praticantes a se convencerem da necessidade de constante ressignificação para com as atuais exigências humanas, sociais e tecnológicas (Campello, 2003).

Nessa perspectiva, este artigo se debruça a caracterizar a competência em informação como movimento de inovação social, além de apresentar noções conectivas entre as temáticas, abordando aspectos entre as duas principais temáticas com caráter predominantemente qualitativo. Trata-se, portanto, de pesquisa em literatura permeada por levantamento bibliográfico. Para vias justificatórias, Minayo (2001) aponta que o objeto das Ciências Sociais - incluindo as aplicadas - é essencialmente qualitativo. A realidade social, ou as discussões em torno desta, consiste no próprio dinamismo da vida individual e coletiva com toda a riqueza de significados embutida nela.

\section{Discussão e ANÁLISE}

\section{Informaçáo e conhecimento para todos?}

As tensões já assinaladas entre os desnivelados pólos da circulação e da apropriação da informação e do conhecimento - amplas condições e larga disseminação, de um lado, e barreiras à sua proliferação e apropriação social, de outro - denotam sérias implicações geopolíticas; o que impulsiona no aumento ou na diminuição das desigualdades mundiais já existentes entre países monetariamente estabilizados e (semi)periféricos no cerne mundial. Uma forte tendência separatista ocorre entre linhas divisórias para com os capacitados a propagar ou a participar ativamente na atual dinâmica ininterrupta de inovação e aprendizado, principalmente em se tratando de grupos socialmente inclinados à marginalização. A premissa aqui indica uma nova forma de inserção "neoperiférica" dos países em desenvolvimento no cenário mundial, derivada e resultante em uma capacidade restrita de geração de conhecimento necessária, assim como uma demanda inexpressiva por esse conhecimento. O resultado disto é a densidade da cavidade entre os mais e menos desenvolvidos, bem como o aumento desenfreado da desigualdade e subdesenvolvimento (Albagli e Maciel, 2011).

Em outros termos, tal circunstância se constitui na porta de entrada para novas hierarquias geopolítico-econômicas, tomando como base diferentes contextos socioespaciais: estrategicamente informações e conhecimentos disponíveis estão torrencialmente desiguais, bem como as assimetrias dentro 
e para com os fluxos e componentes das redes de informação e comunicação existentes (Albagli e Maciel, 2011).

Para melhor compreensão, cabe distinguir que redes de informação e redes de conhecimento são conceituadas e aplicadas distintamente, sendo as últimas mais seletivas, severas e hierarquizadas. A diferenciação entre informação e conhecimento é fundamental, sobretudo porque o conhecimento tácito relevante à aplicação tecnológica do conhecimento de expertise na produção e na inovação estaria restrito aos países avançados em ciência e educação, fazendo a acepção de "transferência tecnológica" empiricamente inatingível. Assim, pode-se refletir sobre a transferência do aprendizado, mas não em transferência de conhecimento, cujo entendimento estabelece as preponderantes divisões sociotecnológicas, o digital divide, quanto ao desenvolvimento dos países na globalização inclina-se no learning divide - as disparidades nas condições de aprendizado (sobretudo no acesso à educação) e as possibilidades de aplicar conhecimento de ponta à solução de problemas, competitivamente intencional. O learning divide seria, por sua vez, a força motriz de um development ou underdevelopment divide (Albagli e Maciel, 2011).

A globalização competitiva, dentre suas inúmeras facetas, aponta para a realidade cada vez mais cerceada de conhecimento, comparecendo este, não mais como possibilidade, mas como condição essencial. Primeiro, a inovação provém do manejo adequado de conhecimento, sobretudo de cariz pós-moderno. Tecnologias, ciência e conhecimento são componentes comuns, compartilhados e de suposta validade genérica, naquilo em são formas, procedimentos e métodos permutáveis, embora retratem, acima de tudo, sociedades específicas de classe eurocêntrica (Demo, 2005).

A intensividade do conhecimento na modernidade capitalista emaranha-se com a própria lógica contraditória do conhecimento, porque o que produz vantagem, também gera, em contrapartida, a desvantagem. Não se trata de globalização que abre horizontes para todos, como se nela coubessem todos e em iguais níveis. Muito pelo contrário: trata-se de globalização feroz, tradicionalmente capitalista, agravada pela inteligência inequívoca e perversamente fragmentada do dito conhecimento igualitário (Demo, 2005).

As medidas de minimização à exclusão não são inovadoras, mas continuam sendo urgentes. A efetivação e o acompanhamento de planos e políticas inclusivos não devem permanecer apenas documentadas. Daí a necessidade do protagonismo de movimentos alternativos no espaço urbano que prestem atenção nas diferentes formas de exclusão social para, posteriormente, adotarse uma abordagem adequada no âmbito do problema que viabilize uma melhoria completa e efetiva (Alvino-Borba e Mata-Lima, 2011). 


\section{Breves consideraçóes sobre a inovaçáo social}

Em consonância e em relação à premissa anterior, a inovação social é considerada um importante movimento alternativo do desenvolvimento urbano, focado na satisfação de necessidades humanas (e no empowerment) por meio da inovação nas relações sociais. Além do mais, ressalta-se que a visão da inovação social está fortemente entrelaçada à lógica e prática da reivindicação social, emergida como antídoto aos processos de alienação para os quais a coletividade vem sendo vítima. Diversas vezes, a inovação recebe definições complexas. Pode-se conceitua-la como "novas ideias que funcionam". Sua breve definição pormenoriza a inovação da melhoria, pois implica apenas uma mudança incremental; e da criatividade e invenção, vitais para a inovação, porém deixam de lado o árduo trabalho de implementação e difusão que torna as ideias promissoras úteis (Moulaert et al., 2007).

A inovação social refere-se às novas ideias que trabalham, antes de tudo, em prol de objetivos sociais. Definido desta forma, o termo tem, potencialmente, característica extensibilidade - abrangendo movimentos em prol de minorias de gênero, novas formas de usar tecnologia móvel, novos estilos de vida, novos produtos e serviços e outros. Pode também ser responsável por englobar atividades inovadoras e serviços que são motivados pelo objetivo de atender a uma necessidade social e que são predominantemente desenvolvidos e difundidos por organizações cujos objetivos primários são sociais. (Moulaert et al., 2007)

Moulaert et al. (2005), elucidam as três dimensões da inovação social que ocorrem sinergicamente:

1. Satisfação das necessidades humanas que atualmente não são satisfeitas, seja porque "ainda não" ou porque "não é mais" percebida como importante pelo mercado ou pelo Estado. A ênfase será disposta na satisfação das necessidades básicas alienadas, embora se admita que elas podem variar entre as sociedades e comunidades.

2. Mudanças nas relações sociais, especialmente no que diz respeito à governança, que permitem a satisfação citada, mas também aumentam o nível de participação de todos, especialmente grupos privados na sociedade (dimensão do processo).

3. Expansão da capacidade sociopolítica e o acesso aos recursos necessários para sedimentar os direitos à satisfação das necessidades e participação humanas (dimensão do empowerment). 
Assim, é pertinente ressaltar que a inovação social não é exclusiva de determinado contexto, e sim, multisetorial. Ou seja, pode ser impulsionada pelo trabalho conjunto político e governamental, pelo mercado, pela academia, por empresas sociais e por organizações de Terceiro Setor. Quanto à sua natureza relacional, ela é geralmente oriunda de novas combinações de elementos existentes, ao invés de ser absolutamente inéditas - daí o entendimento de perpassar as barreiras fronteiriças em organizações, setores ou disciplinas. $\mathrm{O}$ anterior entendimento destaca o papel fundamental de todos os atores conectados em quaisquer sistemas de inovação, incluindo desde o capital financeiro até o capital intelectual (Mulgan et al., 2007).

Contudo, embora a inovação social aconteça ao nosso redor, mesmo que fragmentada, muitas ideias promissoras são censuradas, bloqueadas por interesses ou marginalizadas. Como resultado, muitos problemas sociais permanecem rígidos e estáticos. O desenvolvimento da inovação social deve ser alocado no rol das tarefas mais urgentes, tendo em vista que, no prisma da modernidade, existe uma lacuna ampla e crescente entre a escala dos problemas enfrentados e a escala das soluções oferecidas. Há mais urgência em áreas onde os problemas estão se intensificando (de diversidade e conflito, por exemplo), em cenários cujos modelos existentes falham miseravelmente ou estão estagnados (como o sistema democrático e judiciário); e em áreas cuja difusão da informação e comunicação (envolvendo o uso das tecnologias móveis) são assimétricas (Mulgan et al., 2007).

É importante ressaltar também que a inovação social é atrelada a uma natureza não mercantil, de caráter coletivo e intencional que, simultaneamente, produz e busca modificações benéficas nas relações sociais. Ela requer uma iniciativa que foge à ordem estabelecida, um novo modo de pensar ou agir, permitindo uma mudança social qualitativa, uma alternativa ou até mesmo uma ruptura dos recorrentes processos. Sua grande diferenciação assumida observa-se no âmbito dos processos, podendo se alocar em vários domínios da sociedade, seja nas políticas, em processos ou em produtos. Quanto à mensuração em grau de melhoria e das pessoas que as utilizam e se beneficiam, as inovações sociais podem ser pequenas, médias ou grandes (André e Abreu, 2006). Conforme a sua difusão, propiciam a maior riqueza social da comunidade, do estado e até dos países, na medida em que as pequenas melhorias geradas afetam posteriormente amplas camadas da população (Echevarría, 2008).

Para Hulgard e Ferrarini (2010), a inovação social pode ser entendida como sinônimo de empreendedorismo social, uma vez que ambos destacam a criação de valor social com ênfase na mudança e na necessidade de integração entre processo e resultado. Nas políticas públicas, essa forma de 
inovação se relaciona às estruturas democráticas e participativas dos governos e emerge da relação entre Estado, mercados e sociedade civil. Noutras palavras, inovação social e empreendedorismo social surgem como fatores relevantes na renovação dos serviços de bem-estar e na contribuição para a qualidade cidadã e social.

Em suma, o empreendedorismo social se distingue do empreendedorismo tradicional por quatro características gerais: (1) falha de mercado, em que o empreendedorismo social busca preencher as lacunas que deixadas pelas empresas dos setores tradicionais da economia; (2) missão, cuja missão principal do empreendedorismo social é a criação de valor social, enquanto os demais empreendimentos concentram-se na geração de lucros; (3) mobilização de recursos, num cenário em que o empreendedor social encontra maiores dificuldades ao obter recursos financeiros e humanos, pelo fato de viabilizar "ofertas menos competitivas aos possíveis financiadores ou empregados"; e, por fim, (4) a medida de desempenho, visto que não apresenta medidas tão bem quantificadas em relação aos demais empreendimentos, pelo fato de seus resultados não serem expressos unicamente na monetização da empresa (Ribeiro, Veloso e Vieira, 2009: 3).

Froes e Melo Neto (2002: 9) argumentam que empreendedores sociais são aqueles "[...] que trazem aos problemas sociais a mesma imaginação que os empreendedores do mundo dos negócios trazem à criação de riqueza”. Ou seja, são os responsáveis por transformar ideais em realidade na vida das pessoas e comunidades em vulnerabilidade econômica e social, restaurando positivamente o ambiente a que pertencem e utilizando humanamente o empreendedorismo como agente de mudanças.

Segundo os preceitos trazidos por Martin e Osberg (2007), o empreendedorismo social pode emergir a partir da (1) identificação de uma situação geradora de exclusão e marginalização de uma parcela da sociedade, necessitando de recursos financeiros ou influência política para alcançar qualquer benefício transformador para sua própria condição; da (2) identificação de uma oportunidade para uma proposição de valor social, incluindo a inspiração, criatividade, ação direta, coragem e força, em prol de efetivamente mobilizar a mudança no cenário identificado; e (3) o estabelecimento do equilíbrio na comunidade com o objetivo de garantir um futuro melhor para o grupo alvo e até mesmo para a sociedade em geral.

Já na acepção de Trivedi e Stokols (2011), um dos principais fatores que têm estimulado o crescimento do campo de empreendedorismo social é o sentimento constante de insatisfação com o Estado e com o mercado pelas camadas sociais vulnerabilizadas e alçadas às margens da sociedade. Enquanto o Estado, conduzido pelo governo - a partir de iniciativas pagas por 
meio de tributos recolhidos - mostra-se na maior parte das vezes ineficiente, o mercado, por vezes, não atende completamente às necessidades e desejos de grupos específicos de pessoas, em especial a base da pirâmide, aumentando assim as discrepâncias sociais. O empreendedorismo social se assemelha, logo, a um movimento que surge mediante uma nova configuração da sociedade pós-moderna em que atores, até então dominantes, o Estado e as grandes corporações, passam a incorporar e visibilizar novas iniciativas de indivíduos, isolados ou em pequenos grupos, que visam propor soluções para as demandas consideradas emergentes, ausentes ou deficientes.

Apesar do termo e do conceito de empreendedorismo social serem relativamente contemporâneos, Dees (2001) infere que desde os primórdios da humanidade se denotaram empreendedores sociais, mesmo que a linguagem e a sociedade tenham incorporado este termo há pouco tempo.

Contudo, o empreendedor social deve ser um agente de mudança contínua que busque gerar transformação social, visto que o empreendedorismo social é "uma atividade empreendedora incorporada de um propósito social" (Austin, Stevenson e Wei-Skillern, 2006: 1) e que pode ser definida a partir de três importantes características: a primeira característica visa identificar um estável, e inerentemente injusto estado de equilíbrio em um sistema que causa exclusão, marginalização ou sofrimento de um segmento da humanidade; a segunda característica busca desenvolver, testar, refinar e escalar uma solução que muda o estado equilíbrio observado, implementando uma proposta de valor social com potencial de mudança; enquanto a terceira característica centra-se em instaurar um novo estado de equilíbrio que desencadeia novos valores para a sociedade, liberando potenciais reprimidos ou aliviando vulnerabilidades estruturais (Osberg e Martin, 2015).

Para Yunus (2010), o empreendedorismo social tem a ver com pessoas. Trata-se de uma iniciativa com consequências sociais erguida por um empreendedor com uma visão social. Essa iniciativa pode ser não-econômica, de viés puramente social ou de um negócio com ou sem a possibilidade de lucro.

É necessário, nesse cenário, pensar na inovação social e no empreendedorismo social voltados às novas áreas de atuação, e também com novos desafios, novas demandas e novas exigências para a compreensão e análise dessa prática social e organizacional. Ribeiro, Veloso e Vieira (2009) chamam a atenção para a necessidade de criar um elo estreito entre as atividades teóricas e práticas de inovações e empreendedorismo social, promulgando resultados qualitativos em termos de conhecimento e desenvolvimento de habilidades para o longo da vida. Melo et al. (2010) asseveram que tal integração desempenha valoroso papel socioeconômico, consistindo num espaço ideal para o desempenho contínuo, promovendo a geração de novos empregos, melhoria na renda, e o aumento da equidade social e cognitiva. 
Sendo assim, e ao ser conjecturada como uma solução aos problemas crônicos que não podem ser resolvidos por intermédio da lógica atual que vigora em nossa sociedade, a inovação social também pode ser entendida como uma ruptura de antigos paradigmas e uma nova percepção de como solucionar problemas e desafios crônicos gerados pela atual organização das sociedades modernas centradas no capitalismo tradicional (Caulier-Grice et al., 2012). Seu seio está alocado na efetivação de novas soluções que respondam simultaneamente a dada necessidade social e gerem novas competências, ativos e/ou relacionamentos. Em outros termos, as inovações sociais são boas para a sociedade e aumentam a capacidade do aprendizado contínuo para a ação humana (European Union/The Young Foundation, 2010).

\section{Competência em informaçáo no contexto da assimetria social}

O progresso terreno se desdobra quando as condições de vida das pessoas esmeram, é quando se avança no desenvolvimento humano. A sentença parece ser notória. Entretanto, durante muito tempo foram confundidos indicadores abstratos, camuflando desigualdades e denotando apenas resultados quantitativos relativos ao bem-estar coletivo. Sob esta ótica, o desenvolvimento tecnológico oriundo do século passado gerou novas modalidades de organização social, denominadas "sociedade da informação", do "conhecimento", "contemporânea", etc. A tecnologia baseada em teoria e pesquisas científicas avançadas passaria a dominar o cotidiano, solidificando a ideia de tecnopolis e introduzindo elementos sem os quais a vida humana atual seria inconcebível. É visível que esse processo tenha se tornado uma das maiores pautas de reflexões e problematizações em vários campos do conhecimento (Suaiden e Leite, 2006).

Destarte, ao analisar o período histórico edificado, a tecnologia baseada na ciência é a pedra angular "[...] no processo de desenvolvimento das sociedades. Grande parte da população sequer percebe a presença da pesquisa, da ciência ou da tecnologia no seu dia-a-dia" (Suaiden e Leite, 2006: 99). Algo mais preponderante é a constatação de que o compartilhamento do conhecimento, a transferência de tecnologia e a disseminação crítica e ética da informação não são tratadas com prioridade e equidade. Ademais,

[...] embora em toda a história da humanidade nunca se registrassem mudanças tão rápidas e profundas, uma de suas consequências foi a exclusão digital. O resultado desse processo foi o crescimento da massa de marginalizados, que atinge enormes contingentes da população mundial. Uma sociedade baseada no uso intenso de conhecimento produz simultaneamente fenômenos de maior igualdade 
e desigualdade, de maior homogeneidade e diferenciação. Resulta, fundamentalmente, em priorizar a democratização do acesso aos meios de produção e disseminação do conhecimento socialmente mais significativo. (Suaiden e Leite, 2006: 99).

À proporção que o acesso à informação foi, hipoteticamente, "democratizado", emergiram os requisitos humanos e tecnológicos que passaram a ser as diretrizes adotadas para a inclusão ou a exclusão do meio social. Para se democratizar, de fato, o acesso à informação e sua transformação em conhecimento, é imprescindível a aderência de uma educação básica que seja capaz de dotar as pessoas de habilidades e competência cognitiva necessários para uma atuação mais crítica, tornando-os, efetivamente, integrantes da sociedade globalizada (Suaiden e Leite, 2006).

O aprender a aprender na sociedade - pressuposto básico da competência em informação - representa o passe para a cidadania, e a educação ao longo da vida permite a construção contínua dos conhecimentos. Essa acepção educacional deve permitir ao indivíduo tomar consciência de si mesmo, de seu entorno e possibilitar a cada cidadão desempenhar sua função social no mundo do trabalho e na vida pública. Dito isto, a função vital da educação, como nunca antes visto, "[...] é conferir a todos a liberdade de pensamento, de juízo, de sentimentos e de criatividade, necessárias para que seus talentos alcancem a plenitude e possam seguir sendo artífices, na medida do possível, de seu destino" (Suaiden e Leite, 2006: 100).

A integração do capital humano, tecnológica e social da informação e conhecimento é uma necessidade fundamental e urgente para a ressignificação do cenário social predominante. O cenário impeditivo da premência de remodelar a atual instabilidade social, substituindo-a por um círculo virtuoso, de superação de pobreza, estabilidade social e avanço científico e tecnológico é o grande desafio frente à atualidade, conforme asseveram Suaiden e Leite (2006).

Uma das áreas onde mais se fala de transformação social e inovação é na educação. É também onde menos de inova. Nisso, a aprendizagem tradicionalista dificilmente poderia ser considerada entidade exitosa, por exemplo e em especial, a escola pública; local que sabidamente se aprende muito pouco. Assim, a aprendizagem se estagna na rota secular - não por tentativa de êxito, mas por falhas estruturais do sistema. O processo de aprendizagem não se sustenta pelo que já aprendido. Principalmente, desconstrói. Sobretudo, deve-se aprender a "desaprender", se libertando de entendimentos obsoletos, como, por exemplo, manter didáticas reprodutivas. O desafio é, entre outros, atuar em ambientes de produção de conhecimento contínuos e com consciência crítica, nos quais todos compartilhem e participem democraticamente (Demo, 2010). 


\section{A competência em informaçáo como movimento de inovaçáo social: construindo relaçóes}

A partir desse entendimento, a Organização das Nações Unidas para a Educação, a Ciência e a Cultura (Unesco, 2013) visualiza a competência em informação como primordial na atualidade, visto seu conceito amplo que engloba conhecimentos, habilidades e atitudes que permitem aos indivíduos e grupos:

- Compreender o papel e as funções midiáticas e de outros fornecedores de informação nas sociedades democráticas, bem como compreender as condições sob as quais essas funções podem ser utilizadas.

- Reconhecer e articular uma necessidade de informação.

- Localizar e acessar informações relevantes.

- Avaliar criticamente as informações e o conteúdo das mídias e outras informações, em foco as dispostas na internet em termos de autoridade, credibilidade e propósito atual.

- Extrair e organizar informações e conteúdos informacionais.

- Sintetizar ou operar nas ideias compreendidas do conteúdo.

- Comunicar ética e responsavelmente a compreensão do conhecimento adquirido.

- Ser capaz de aplicar habilidades das TIC para processar informações e produzir conhecimento.

- Envolver-se com meios de comunicação e outros provedores de informação, incluindo os da internet para a autoexpressão, a liberdade de expressão, o diálogo intercultural e a participação democrática (Unesco, 2013).

Desse modo, sua multiplicidade de utilização pode ser incorporada às ações integradas e integradoras para oportunizar a construção de conhecimento e a consciência essencial da informação para todos. Por ser uma temática que permeia todo e qualquer processo de aprendizado, investigação, criação, resolução de problemas e tomada de decisão, seu fazer vai além das fronteiras da Biblioteconomia e constitui um movimento transdisciplinar mundial, ainda que amparada em distintas denominações e ênfases (Belluzzo, 2018).

Apesar disso, a legitimação da competência em informação como movimento de abrangência mundial é uma adversidade para os países em desenvolvimento, principalmente para o Brasil, que prossegue sua luta contra o analfabetismo, a fome, as extremas discrepâncias de condições sociais, etc. (Dudziak, 2008). 
Isto evidencia a emergência dessa metacompetência para o Brasil, o que indica fortemente a necessidade da difusão de experimentações e vivências aplicáveis à realidade brasileira para os desafios que exigem e implicam na redução das vulnerabilidades sociais e desigualdades regionais no concernente às políticas de acesso e uso da informação para o exercício da cidadania e o aprendizado ao longo da vida (Belluzzo, 2014).

Além da divulgação de manifestos e declarações como um pré-requisito educativo para o desenvolvimento, inovação e inclusão social, é preciso que ocorram ações de democracia e exercício pleno da cidadania, sendo o seu desenvolvimento priorizado para grupos/comunidades considerados vulneráveis (mulheres, crianças, idosos, portadores de deficiências etc.), sendo aqueles que se encontram em situações de discriminação, intolerância e fragilidade e que estão em desigualdade e desvantagem na sociedade atual, principalmente, em relação às questões que envolvem o acesso e uso da informação para a construção de conhecimento, identidade e autonomia a fim de permitir a sua efetiva inclusão social (Belluzzo, 2018).

Em similaridade, essas são algumas das esferas sociais/nacionais em que se constatam déficits de inovação particularmente graves, e também oportunidades para novas soluções criativas, tais como: o aumento da expectativa de vida, que requer novas maneiras de organizar tratamentos de saúde, cuidados e apoio mútuo; multiculturalismo crescente de países e cidades, que exige formas inovadoras de organizar a escolaridade, a alfabetização e a moradia para evitar a segregação e o conflito; as grandes desigualdades, que se ampliaram em muitas sociedades e tendem a estar associadas com muitos outros males sociais, que vão da violência física à doença mental; e a promoção do bem-estar subjetivo, o qual exige novas formas de pensar sobre políticas públicas e ação civil (Mulgan et al., 2007).

Em cada um desses campos citados e em outros, muitos dos modelos dominantes existentes simplesmente não funcionam bem o suficiente. Muitas vezes são inflexíveis e sem criatividade. A causa mortis consiste no foco aos problemas passados ou na limitação por interesses alheios, tanto quanto podem ser fornecidos por agências que se tornaram complacentes ou desatualizadas. O resultado é o sofrimento humano desnecessário e o potencial exacerbado (Mulgan et al., 2007).

Por esse ângulo, a Unesco (2013) aponta quatro pilares essenciais para o desenvolvimento de sociedades do conhecimento equitativo e que se assemelha com os contextos inferidos por Mulgan et al. (2007).: igualdade de acesso à educação de qualidade para mulheres, homens e crianças; o multiculturalismo, dando expressão à diversidade cultural, incluindo as dimensões de gênero culturais; acesso universal da informação à mulheres, homens e 
crianças, especialmente àquela de domínio público; e liberdade de expressão, com ênfase na igualdade de gênero (Unesco, 2013).

Destarte, a Tabela 1 ilustra a competência em informação como movimento "linkado" às premissas da inovação social e do desenvolvimento das sociedades do conhecimento:

\begin{tabular}{|c|c|}
\hline $\begin{array}{l}\text { Princípios da inovação social/sociedades } \\
\text { do conhecimento }\end{array}$ & $\begin{array}{l}\text { Possiveis relações com a competência em } \\
\text { informação }\end{array}$ \\
\hline $\begin{array}{l}\text { 1) Igualdade de acesso à educação de qualida- } \\
\text { de para todos }\end{array}$ & $\begin{array}{l}0 \text { acesso à informação é um requisito necessário } \\
\text { para alcançar a educação em larga escala. A com- } \\
\text { petência em informação abrange as habilidades, } \\
\text { técnicas e atitudes para acessar, avaliar e usar de } \\
\text { maneira efetiva e ética os fornecedores de infor- } \\
\text { mações, mídia e outros provedores de conteúdos. } \\
\text { Também se relaciona à educação de qualidade, } \\
\text { uma vez que elucida a necessidade de uma } \\
\text { definição ampliada para a alfabetização ao longo } \\
\text { da vida. }\end{array}$ \\
\hline $\begin{array}{l}\text { 2) Multiculturalismo e aumento da expectativa } \\
\text { de vida }\end{array}$ & $\begin{array}{l}\text { Os meios de comunicação midiáticos e digitais, } \\
\text { as bibliotecas e demais unidades de informação e } \\
\text { transmissores de cultura são os motores propulso- } \\
\text { res da globalização cultural. } \\
\text { Pela via da competência em informação promo- } \\
\text { ve-se o multiculturalismo e as habilidades para } \\
\text { usar os meios de comunicação disponíveis na } \\
\text { manifestação das expressões culturais e do diálogo } \\
\text { e para analisar e avaliar criticamente a represen- } \\
\text { tação de várias culturas e povos pela mídia e outros } \\
\text { provedores de conteúdos. } \\
\text { Além disso, contribui para o aumento da expec- } \\
\text { tativa de vida ao promover o diálogo inclusivo e } \\
\text { tolerante às diferenças humanas. }\end{array}$ \\
\hline $\begin{array}{l}\text { 3) Acesso universal da informação a todos e } \\
\text { diminuição da desigualdade }\end{array}$ & $\begin{array}{l}0 \text { acesso amplo à informação por meio de políticas, } \\
\text { leis e regulamentos só é efetivo se desenvolvidas } \\
\text { as noções e habilidades necessárias para usufruir } \\
\text { destas oportunidades. } \\
\text { Ao desenvolver a competência em informação } \\
\text { a pessoa também desenvolve habilidades } \\
\text { necessárias para a asserção anterior e, conse- } \\
\text { quentemente, para a diminuição da desigualdade } \\
\text { informacional. }\end{array}$ \\
\hline
\end{tabular}




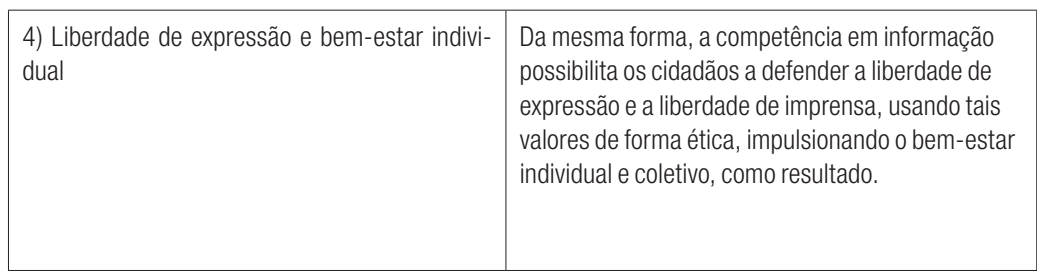

Tabela 1. Competência em informação e relações com a inovação social e as sociedades do conhecimento Fonte: Unesco (2013) e Mulgan et al. (2007)

Consoante à visualização da Tabela 1, identifica-se que a educação, por meios formais e não formais é fundamental para promover a liberdade de expressão e o acesso à informação nas sociedades contemporâneas. A competência em informação, nesse sentido, abrange um arcabouço multidisciplinar que habilita as pessoas a exercerem a cidadania a partir do acesso, recuperação, assimilação, avaliação, uso, criação e compartilhamento de informações e conteúdos de mídia em todos os formatos; utilizando múltiplas ferramentas de forma ética e eficaz, a fim de participar e se engajar em atividades pessoais, profissionais e sociais. É notória a necessidade progressiva dessa metacompetência ao longo da vida, objetivando contribuir significativamente para o desenvolvimento pessoal, profissional e social. Sua efetivação deve ser refletida nas políticas nacionais de educação para promovê-lo como um marco de inovação na elaboração de resultados institucionais e de programas entre instituições educacionais (Unesco, 2015).

Para tanto, apresenta-se o Modelo de Exploração, Engajamento e Empoderamento, ou "Modelo E Triplo" da competência em informação, visto como possível forma de inovação social.

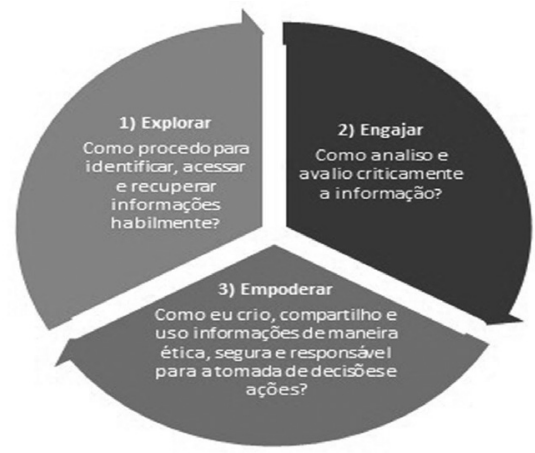

Figura 1. Modelo de Exploração, Engajamento e Empoderamento Fonte: adaptado de Unesco (2015) 
Com base na Figura 1 e nos pressupostos da competência em informação como movimento da inovação social, seu agrupamento se exibe nessas três grandes aplicações práticas, a saber: explorar consiste em identificar, acessar e recuperar informações habilmente; engajar se baseia em analisar e avaliar a informação criticamente; e empoderar implica em criar ou produzir, compartilhar ou comunicar e usar informações de maneira ética, segura e responsável para a tomada de decisões e de atitudes (Unesco, 2015).

Ao analisar os padrões e indicadores para o uso da competência em informação junto às dimensões e aos meios de uma inovação social, partindo das perspectivas de Belluzzo, Tardif e Harrisson, apontam-se as possíveis relações entre esses, conforme a Tabela 2 mostra:

\begin{tabular}{|l|l|}
\hline \multicolumn{1}{|c|}{$\begin{array}{c}\text { Padrões e Indicadores para o uso da Competência em } \\
\text { Informação (Belluzzo, 2007) }\end{array}$} & \multicolumn{1}{|c|}{$\begin{array}{c}\text { Dimensões e meios da inovação } \\
\text { social }\end{array}$} \\
\hline $\begin{array}{l}\text { Padrão 1: A pessoa competente em informação determina a } \\
\text { natureza e a extensão da necessidade de informação. }\end{array}$ & Aprendizagem \\
\hline $\begin{array}{l}\text { Padrão 2: A pessoa competente em informação acessa a } \\
\text { informação necessária com efetividade. }\end{array}$ & Empowerment \\
\hline $\begin{array}{l}\text { Padrão 3: A pessoa competente em informação avalia critica- } \\
\text { mente a informação e as suas fontes. }\end{array}$ & Avaliação \\
\hline $\begin{array}{l}\text { Padrão 4: A pessoa competente em informação, individual- } \\
\text { mente ou como membro de um grupo, usa a informação com } \\
\text { efetividade para alcançar um objetivo/obter um resultado. }\end{array}$ & Integração \\
\hline $\begin{array}{l}\text { Padrão 5: A pessoa competente em informação compreende as } \\
\text { questões econômicas, legais e sociais da ambiência do uso da } \\
\text { informação e acessa e usa a informação ética e legalmente }\end{array}$ & Difusão \\
\hline
\end{tabular}

Tabela 2. Relações entre os padrões e indicadores para o uso da competência em informação e as dimensões e meios da inovação social Fonte: adaptado de Belluzzo (2007) e Tardif e Harrisson (2005)

Os padrões e indicadores utilizados para diagnóstico da competência em informação podem também servir como aporte aos estudos relacionados desse movimento ao movimento da inovação social. Nessa significação, é pertinente utilizar os padrões e indicadores de competência em informação para medir as etapas de modelos da inovação social (Ottonicar, Bassetto e Nascimento, 2018).

A competência em informação abrange as habilidades, capacidades e experiências individuais ao longo de sua vida (Belluzzo, 2007; ALA/ACRL, 2016). É componente dos múltiplos contextos sociais, ou seja, a participação cidadã e seu desdobramento na inclusão social. Logo, para ser competente em usar a informação de maneira concisa é preciso, de antemão, adquirir um 
comportamento proativo: um perfil sagaz que busque conhecer e aprender aquilo que não se sabe, "sair da zona de conforto", visto que se tem a tendência de procurar saber/conhecer o mínimo possível. Esse comportamento proativo é viabilizado mediante a comunicação humana (Ottonicar, Bassetto e Nascimento, 2018).

\section{Conjecturando possíveis aplicaçóes: Inovaçáo Social, Ciência da Informação e Competência em Informação}

Cabe, aqui, o questionamento: como se integrar, factualmente, a aplicação da inovação social nos canais ativos da Ciência da Informação e na aprendizagem continuada? Isso é uma conjectura que se deve pensar e buscar a feição, principalmente em países cuja discussão e difusão ainda carece de avanço, como o Brasil.

Novos paradigmas e referenciais começam a apresentar um potencial de atendimento às necessidades sociais. Surge, então, o conceito de inovação social como ponto de partida para a construção de um novo modelo para atendimento às demandas sociais com respeito à diversidade e à unidade humana, e que contribua para a promoção da igualdade na sociedade contemporânea. Por conseguinte, e buscando conjecturar possíveis realizações empíricas em inovação social para a CI e a CoInfo, faz-se tal "costura" com os três paradigmas organizados por Capurro (2003): o Paradigma Físico, que postula a presença de algo, um artefato físico transmitido pela relação emissor/receptor; o Paradigma Cognitivo, cuja premissa aponta a busca de informação motivada pela necessidade cognitiva anômala (information need); e o Paradigma Social, que vislumbra representar o conhecimento por meio de uma linguagem social e direcionada.

Para melhor visualização do exposto, a Tabela 3 evidencia esta proposição:

\begin{tabular}{|l|l|}
\hline \multicolumn{1}{|c|}{ Preceitos da inovação social } & \multicolumn{1}{|c|}{$\begin{array}{c}\text { Possíveis aplicações paradigmáticas na Cl } \\
\text { (Capurro, 2003) e na Colnfo }\end{array}$} \\
\hline Introdução de novos métodos de produção & $\begin{array}{l}\text { Paradigma físico (objeto físico transmitido entre emis- } \\
\text { sor/receptor): a implementação de um produto (bem } \\
\text { ou serviço) novo ou significativamente melhorado, } \\
\text { ou um processo, ou um novo método de marketing, } \\
\text { ou um novo método organizacional nas práticas pro- } \\
\text { fissionais ou em relações externas - o aprendizado } \\
\text { ao longo da vida. }\end{array}$ \\
\hline
\end{tabular}




\begin{tabular}{|l|l|}
\hline $\begin{array}{l}\text { Articulação de uma ordem social que permita a } \\
\text { melhor harmonização entre as necessidades e } \\
\text { inclinações pessoais dos indivíduos }\end{array}$ & $\begin{array}{l}\text { Paradigma cognitivo (necessidades de informação): } \\
\text { 0 apoio no desenvolvimento da sociedade para } \\
\text { que não apenas alguns, mas a totalidade de seus } \\
\text { membros tenha a oportunidade de elucidar suas } \\
\text { necessidades eventuais e constantes de informação } \\
\text { - a ênfase na promoção da cidadania ativa. }\end{array}$ \\
\hline Investimento social tangível e mensurável & $\begin{array}{l}\text { Paradigma social (atuação social da informação): } \\
\text { o investimento social é um diferencial percebido } \\
\text { na atualidade, e, portanto, é fator indiscutível de } \\
\text { agregação de valor científico/informacional para o } \\
\text { eixo social - principalmente em se tratando de uma } \\
\text { ciência e uma subárea predominantemente sociais. }\end{array}$ \\
\hline
\end{tabular}

Tabela 3. Inovação social, Ciência da Informação e competência em informação: possíveis aplicações Fonte: Farfus e Rocha (2007) e Capurro (2003)

De natureza igual, quando a ideia de uma informação percebida como valor socialmente econômico e inovador passa a ser disseminada e promulgada, passamos a dar ensejo ou construir os pilares de uma sociedade centrada na troca de informação e aprendizagem contínua. Dessa forma, a inovação social unida à informação - e vice-versa - revalidaria toda a estrutura social, desde a produção de bens sociais (que poderiam agora ser intangíveis) até às mais altas esferas de poder decisório às necessidades de informação individuais e coletivas (que estariam mais suscetíveis à influência da informação). (Renault e Cabral, 2007).

\section{Considerações finais}

Apesar das barreiras sociais e econômicas preponderantes, as inovações sociais evoluem pelas trilhas do aprendizado contínuo e colaborativo, transformando as ideias em formas atuais e correspondentes às sociedades modernas. Novos modelos de colaboração coletiva vêm auxiliando a compreender mais sofisticadamente como a aprendizagem contínua é essencial à cidadania, sociedade, economia e tecnologia (Mulgan et al., 2007).

Portanto, a validação da competência em informação como movimento de inovação social se dá pela premência do "aprender a aprender", impulsionado pela reorganização da informação e do conhecimento contemporâneo, uma vez que é necessário para as pessoas o entendimento e o reconhecimento das necessidades de informação, como se a utiliza e como se procede ao processo de comunicação do conhecimento gerado. 
À vista disso, considera-se a competência em informação e sua função social vital para qualquer tipo de sociedade, tanto quanto para qualquer tipo de organização e, por isso, perpassa os limites territoriais das bibliotecas. A informação, quando tratada como como matéria-prima, se constitui em insumo básico de fluxos e processos sociais, a comunicação como meio de disseminação e as tecnologias da informação como infraestrutura de armazenagem, processamento e acesso - daí o inerente papel dessa metacompetência num contexto híbrido (Belluzzo, 2018).

Ressignificar a história é responsabilidade daqueles que estão comprometidos com a remodelação de uma sociedade com mais justiça e igualdade, assegurada pelo processo solidário entre os indivíduos. Visto que a solidariedade é um modo altruistamente genuíno de conhecimento - obtido pelo reconhecimento empático do outro, esse outro só pode ser (re) conhecido como produtor de conhecimento. Sem embargo, todo o conhecimento-emancipação terá uma índole multicultural.

No âmbito das ciências sociais aplicadas, variadas abordagens são necessárias para a formação de um cenário. Posto isto, a observação de diferentes conjunturas contextuais, - aqui discutindo sobre a competência em informação como movimento da inovação social - impulsiona os estudos futuros a utilizarem esse para averiguar as possibilidades de novas perspectivas para as áreas, a fim de identificar e/ou constituir mecanismos que tencionem o aprendizado contínuo e inovador de coletividades democráticas.

Quanto à solidificação da da CoInfo movimento de inovação social, dadas as aplicabilidades paradigmáticas, pode-se apontar que numa primeira instância, o dito movimento pode surgir na esfera da psique, como ideia ou força motriz. Força motriz que se materializa e/ou se "coisifica" em ações socialmente efetivas. Contudo, essa sistemática, mesmo se desenhada numa esfera "micro", se situa em uma realidade integral: contextos que asseveram sentido e subjetividades à Ciência da Informação, dispondo ordem nas relações sociais.

\section{REFERÊNCIAS}

Albagli, Sarita, e Maria Lucia Maciel. 2011. "Informação, poder e política: a partir do Sul, para além do Sul”, in Informação, conbecimento e poder: mudança tecnológica e inovação social, Sarita Albagli e Maria Lucia Maciel, 09-39. Rio de Janeiro: Garamond.

Alvino-Borba, Andreilcy e Herlander Mata-Lima. 2011. "Exclusão e Inclusão Social nas Sociedades Modernas: um olhar sobre a situação em Portugal e na União Europeia". Serviço Social Es Sociedade (106): 219-240.

http://www.scielo.br/pdf/sssoc/n106/n106a03.pdf 
ALA/ACRL (American Library Association/Association of College \& Research Libraries). 2016. "First part of the draft framework for information literacy for higher education". Chicago: ALA.

http://www.ala.org/acrl/sites/ala.org.acrl/files/content/issues/infolit/Framework_ ILHE.pdf

André, Isabel e Alexandre Abreu. 2006. "Dimensões e espaços da inovação social." Finisterra (Centro de Estudos Geograficos (IGOT), Universidade de Lisboa) 41 (81): 121-141. https://revistas.rcaap.pt/finisterra/article/view/1465

Austin, James, Howard Stevenson e Jane Wei-Skillern. 2006. "Social and commercial entrepreneurship: same, different, or both?" Journal of Baylor University 30 (1): $1-22$.

http://www.scielo.br/pdf/rausp/v47n3/03.pdf

Bauman, Zygmunt. 1999. Globalização: as consequências bumanas. Rio de Janeiro: J. Zahar.

Belluzzo, Regina Célia Baptista. 2014. "O conhecimento, as redes e a competência em informação (Coinfo) na sociedade contemporânea: uma proposta de articulação conceitual”. Perspectivas em Gestão \& Conhecimento (João Pessoa) 4 (Número Especial): 48-63. http://periodicos.ufpb.br/ojs2/index.php/pgc

Belluzzo, Regina Célia Baptista. 2018. A competência em informação no Brasil: cenários e espectros. São Paulo: ABECIN Editora.

Belluzzo, Regina Célia Baptista. 2007. Construção de mapas: desenvolvendo competências em informação e comunicação. Bauru: Cá Entre Nós.

Bignetti, Luiz Paulo. 2011. "As inovações sociais: uma incursão por ideias, tendências e focos de pesquisa”. Ciências Sociais Unisinos 47 (1): 03-14. http://revistas. unisinos.br/index.php/ciencias_sociais/article/view/1040/235

Campello, Bernadete. 2003. "O movimento da competência informacional: uma perspectiva para o letramento informacional”. Ciência da Informação 32 (3): 28-37. http://bogliolo.eci.ufmg.br/downloads/CAMPELO\%20Competencia\%20Informacional.pdf

Capurro, Rafael. 2003. "Epistemologia e Ciência da Informação”, in V Encontro Nacional de Pesquisa em Ciência da Informação, 5., Belo Horizonte, 2003. Anais... Belo Horizonte: Escola de Ciência da informação da UFMG.

Caulier-Grice, Julie, Anna Davies, Robert Patrick e Will Norman. 2012. “Defining Social Innovation", in The Young Foundation Social Innovation Overview: a deliverable of the project. European Commission - 7th Framework Programme. Brussels: DG Research.

Dees, J. Greg. 2001. The Meaning Of Social Entrepreneurship. Kauffman Center For Entrepreneurial Leadership: Kansas City, MO.

Demo, Pedro. 2000. "Ambivalências da sociedade da informação". Ciência da Informação (Brasília) 29 (2): 37-42. http://www.scielo.br/pdf/\%0D/ci/v29n2/a05v29n2.pdf

Demo, Pedro. 2002. Complexidade e Aprendizagem: a dinâmica não linear do conhecimento. São Paulo: Atlas.

Demo, Pedro. 2005. "Conhecimento e vantagem comparativa". O público e o privado, 5. http://www.seer.uece.br/?journal=opublicoeoprivado\&page=article\&op=view \&path $\% 5 \mathrm{~B} \% 5 \mathrm{D}=255 \&$ path $\% 5 \mathrm{~B} \% 5 \mathrm{D}=378$ 
Demo, Pedro. 2010. "Rupturas urgentes em educação”. Ensaio: Avaliação e Políticas Públicas em Educação 18 (69): 861-872. http://www.scielo.br/pdf/ensaio/v18n69/v18n69a11.pdf

Dudziak, Elisabeth Adriana. 2001. "A information literacy e o papel educacional das bibliotecas”. Dissertação (Mestrado), Programa de Pós-Graduação em Ciências da Comunicação, Escola de Comunicações e Artes, Universidade de São Paulo (USP), São Paulo.

Dudziak, Elizabeth Adriana. 2008. "Os faróis da sociedade de informação: uma análise crítica sobre a situação da competência em informação no Brasil”. Informação ESociedade: Estudos 18 (2): 41-53.

http://www.periodicos.ufpb.br/ojs/index.php/ies/article/view/1704/2109

Echevarría, Javier. 2008. "El Manual de Oslo e la Innovación Social”. ARBOR Ciência, Pensamiento e Cultura. CLXXXIV 732: 609-619.

European Union/The Young Foundation. 2010. Study on SI. Report prepared by the Social Innovation exchange (SIX) and the Young Foundation for the Bureau of European Policy Advisors.

https://youngfoundation.org/wp-content/uploads/2012/10/Study-on-Social-Innovation-for-the-Bureau-of-European-Policy-Advisors-March-2010.pdf

Farfus, Daniele e Maria Cristhina de Souza Rocha, org. 2007. Inovações sociais. Coleção Inova, v. 2. Curitiba: SESI/SENAI/IEL/UNINDUS.

Froes, César e Francisco Melo Neto. 2002. Empreendedorismo social: a transição para a sociedade sustentável. Rio de Janeiro: Qualitymark.

Hulgard, Lars e Adriane Vieira Ferrarini. 2010. "Inovação social: rumo a uma mudança experimental na política pública?” Ciências Sociais Unisinos 46 (3): 256-263. http://revistas.unisinos.br/index.php/ciencias_sociais/article/view/691

Martin, Roger L. e Sally Osberg. 2007. "Social entrepreneurship: The case for a definition". Stanford Social Innovation Review 5 (2): 29-39.

https://www.law.berkeley.edu/php-programs/courses/fileDL.php?fID=7288

Melo, Marlene Catarina de Oliveira Lopes, Cristiana Fernandes De Muylder, Ana Lúcia Magri Lopes, Meire Rose de Oliveira Loureiro Cassini e Natália Guerra Rabelo. 2010. "O empreendedorismo e o papel das incubadoras para as empresas graduadas de base tecnológica da região metropolitana de Belo Horizonte”. Revista INGEPRO 2: 50-62.

Minayo, Maria Cecília de Souza. 2001. Pesquisa Social: teoria, método e criatividade. 18 ed. Petrópolis: Vozes.

Moulaert, Frank, Flavia Martinelli, Erik Swyngedouw e Sara González. 2005. "Towards Alternative Model(s) of Local Innovation". Urban Studies 42 (11): 1969-1990. https://pdfs.semanticscholar.org/7ce0/e41d745fccc2dd4c373e79f53e0bc2c87b56.pdf

Moulaert, Frank, Flavia Martinelli, Sara González e Erik Swyngedouw. 2007. "Introduction: Social Innovation and Governance in European Cities". European Urban and Regional Studies 14 (3): 195-209.

Mulgan, Geoff, Tucker, Simon, Ali, Rushanara e Sanders, Ben. 2007. Social innovation: what it is, why it matters and how it can be accelerated. Skoll Centre for Social Entrepreneurship. London: The Young Foundation.

Osberg, Sally, e Martin, Roger. 2015. Getting beyond better: how social entrepreneurship works. Boston: Harvard Business Review Press. 
Ottonicar, Selma Leticia Capinzaiki, Clemilton Luis Bassetto e Natália Marinho do Nascimento. 2018. "O comportamento informacional e a competência em informação: uma abordagem para geração de inovação em micro e pequenas empresas". Encontros Bibli: revista eletrônica de biblioteconomia e ciência da informação 23 (52): 18-33.

https://periodicos.ufsc.br/index.php/eb/article/view/1518-2924.2017v23n52p18/36456

Oviedo, Rafael Antônio Malagón e Dina Czeresnia. 2015. "O conceito de vulnerabilidade e seu caráter biossocial”. Interface (Botucatu) 19 (53): 237-250. http://www.scielo.br/pdf/icse/2015nahead/1807-5762-icse-1807-576220140436.pdf

Renault, Leonardo Vasconcelos e Ana Maria Rezende Cabral. 2007. "Paradigmas e modelos em Ciência da Informação”, in VIII ENANCIB - Encontro Nacional de Pesquisa em Ciência da Informação, 8., 2007, Salvador. Anais... Salvador: ANCIB.

Ribeiro, Filipe A., Ana N. Veloso e Artur V. Vieira. 2009. "Empreendedorismo social: uma análise via associativismo juvenil”. FEP Working Papers (Universidade do Porto, Faculdade de Economia do Porto) 330: 1-26. https://ideas.repec.org/p/por/fepwps/330.html

Suaiden, Emir José e Cecília Leite. 2006. "Dimensão social do conhecimento”, in Inteligência, informação e conbecimento, Kira Tarapanoff, 99-114. Brasília: IBICT, Unesco.

Tardif, Carole e Denis Harrisson. 2005. Complémentarité, convergence et transversalité: la conceptualisation de l'innovation sociale au CRISES. Québec: Centre de Recherche Sur Les Innovations Sociales Cahiers du CRISES.

Trivedi, Chitvan e Daniel Stokols. 2011. "Social enterprises and corporate enterprises: fundamental differences and defining features". Journal of entrepreneurship 20 (1): $1-32$. https://journals.sagepub.com/doi/pdf/10.1177/097135571002000101

Unesco (Organização das Nações Unidas Para a Educação, a Ciência e a Cultura). 2013. Media and Information Literacy: policy and strategy guidelines. Paris: Unesco.

Unesco. 2015. Media and Information Literacy for the Sustainable Development Goals. Gothenburg: Nordicom.

Yunus, Muhammad. 2010. Building social business: The new kind of capitalism that serves humanity's most pressing needs. New York: PublicAffairs.

Para citar este texto:

Righetto, Guilherme Goulart y Elizete Vieira Vitorino. 2020. "A competência en informação como movimento de inovação social”. Investigación Bibliotecológica: archivonomía, bibliotecología e información 34 (82): 29-52. http://dx.doi.org/10.22201/iibi.24488321xe.2020.82.58080 